\title{
Korruption in jeder Weltecke?
}

Elmar Koenen

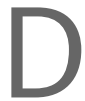
as wäre sicher die Einschätzung von Oberstaatsanwalt Schaupensteiner aus Frankfurt, dem verdienten Kammerjäger der deutschen Korruptionsbekämpfung. Einmal mehr kann er seine These von der Allgegenwart korruptiver Vorgänge durch die Gepflogenheiten an der Spitze der Bundesbank und insbesondere dem dort chronischen Mangel an Schuldeinsicht bestätigt sehen: Wo immer öffentliche Gelder fließen und großzügige Privilegien gewährt werden, so hat er oft genug gezeigt, wird jede genauere Recherche fündig. Sie trifft dort auf gut gehende Geschäfte, Täter ohne unmittelbare Opfer, stabile Vertrauensbeziehungen, funktionierende soziale Netze - alles Elemente, die den Mangel an Unrechtsbewusstsein bei den Beteiligten plausibel machen. Tritt jedoch plötzlich der Skandalfall ein, machen Medien oder Ermittler einen Korruptionsfall sichtbar, kann nicht gewesen sein, was nicht sein darf. Dann fällt die Empörung besonders heftig aus, größer als bei ,normaler' Schwerkriminalität. Natürlich gilt auch Kriminalität als ein Übel, von dem man weiß, das man es nicht loswird; vom Krebsgeschwür,Korruption' aber muss man - gegen besseres Wissen - behaupten, dass man es ausmerzen kann und muss. Die Semantik der Korruption scheint ins Selbstbild der im Prinzip ,guten' Gesellschaft nicht integrierbar, obwohl sich die Praktiker unter den Experten einig sind, dass der ,Krieg gegen die Korruption' nicht zu gewinnen ist. Die Bilder, die wir uns von unserer Gesellschaft machen, sind offenbar auch in wesentlichen Punkten unvollständig. Wie könnten Korrekturen unseres Bilder über Abweichung und Normbefolgung aussehen, welches sozialwissenschaftliche und kriminologische Wissen müsste öffentlich kommuniziert werden, welche Fächer und Disziplinen und Disziplinen wären hier gefordert?

Traditionell dominiert eine bestimmte Lesart das Thema, nämlich der Versuch, Phänomene wie Korruption strafrechtlich zu bekämpfen mit dem illusorischen Ziel ihrer Verhinderung durch langfristig sich verschärfende Sanktionen. Unterstützt wird dies durch kriminologische Analysen der (angeblich) unzureichenden Implementation des geltenden Strafrechts. Seit einigen Jahren sind Betriebswirtschaftslehre und Organisationstheorie mit spieltheoretischen und rational-choice Rekonstruktionen hinzugekommen. In ihren je spezifischen praktischen Perspektiven zeigen weder Strafrecht noch BWL ein ausgeprägtes Interesse an tiefenscharfen Beobachtungen und theoretisch anspruchsvollen Erklärungen von Korruption. So verzichten sie z.B. darauf, den sich aufdrängenden Zusammenhang von Korruptionswachstum und dem, unter neoliberalisierten Verhältnissen gestiegenen Konkurrenzdruck ins Auge zu fassen. Auch entgeht ihnen der für das Verhältnis von Amtsinhaber und Klient folgenreiche Machtverlust von Politik und Verwaltung im Verhältnis zur Wirtschaft. Auf die Verwendung öffentlicher Mittel nehmen Unternehmen nun immer direkter, aber nach wie vor ohne politische Legitimation Einfluss. Unter den Bedingungen langfristig schwacher Konjunktur kommt die Politik den wirtschaftlichen Akteuren inzwischen so weit entgegen, dass sie auf die klassischen Formen der Korruption zunehmend verzichten können. Der Klient hat sich vom Bittsteller um öffentliche Aufträge zum empfindlichen Star gewandelt, der den politischen Amtsinhabern die Bedingungen diktiert, unter denen er unter (besonders attraktiven) Umständen bereit ist, $\mathrm{zu}$ investieren. Die Machtverschiebungen hin zum Kurzschluss zwischen Politik und Ökonomie müssten aber auch Gesetzgebung und Rechtsprechung berücksichtigen.

Solche Zusammenhänge legen nah, Korruption nicht länger als quasi-anthropologische Größe, als verdrängte Unnatur, als Krankheit und -Krebsleiden mißzuverstehen. Eine Gesellschaft wäre nicht als ein von Ausschlag befallener Körper $\mathrm{zu}$ begreifen, sondern als $\mathrm{Zu}$ sammenhang, der intelligent genug ist, auch seine negatorischen Momente als integrale Bestandteile anzuerkennen. Verstehen lässt sich Korruption z.B. als soziale Beziehung (Höffling 2002), die deutliche Spuren ihrer spezifisch gesellschaftlichen Herkunft trägt. Unter funktionalen Gesichtspunkten stellt sich dann z.B. auch die provokative Frage: Wieviel Korruption braucht die Demokratie? (Raith 1996). Distanz zur politisch korrekten Perspektive der Bekämpfung zeigt auch der französische UN-Politiker Jean-Marie Ghéhenno (1994) mit seinem Hinweis auf die sozial ungleich verteilten Chancen zu korruptem Handeln. Und dass Korruption z.B. in Italien die doppelte Prägung ihrer durch politischen Klientilismus und außerstaatlich organisierte Gewalt gezeichneten Gesellschaft aufweist, liegt auf der Hand.
Solche sozialtheoretisch motivierte Sichtweisen sehen sich oft dem Verdacht der Verharmlosung korruptiver Phänomene ausgesetzt. Doch das deutende Verstehen zielt nicht notwendig auf ein Verständnis, das dem gesellschaftlichen $\mathrm{Zu}$ sammenhang neben der Verursachung auch noch die Schuld zuschiebt. An dieser täterentlastenden Vereinseitigung hat die sozialwissenschaftliche Aufklärung des Strafrechts in den 70er Jahren gekrankt). Erst die Rekonstruktion korrupten Handelns und Verhaltens aus seinen sozialen, politischen und ökonomischen Bedingungen lässt die individuellen und kollektiven Zwangslagen und Konflikte verstehen, aus denen heraus 